www.jmscr.igmpublication.org

Impact Factor 5.84

Index Copernicus Value: 83.27

ISSN (e)-2347-176x ISSN (p) 2455-0450

crossref DOI: https://dx.doi.org/10.18535/jmscr/v5i1.51

Journal Of Medical Science And Clinical Research

\title{
Quality Assurance Guided FISH-Analysis for Optimal Detection of AML- Associated Chromosomal Aberrations
}

Authors

\section{Dina Adel Fouad Mohamed', Nevine Nabil Mostafa ${ }^{2}$, Yasmin Nabil Salem³, Mona Fathey Abdel Fattah ${ }^{4}$}

${ }^{1}$ MD Clinical Pathology, Professor of Clinical Pathology, Clinical Pathology Department, Hematology Unit, Faculty of Medicine, Ain Shams University, Cairo, Egypt.

${ }^{2}$ MD Internal Medicine, Professor of Clinical Haematology Internal Medicine Dept Faculty of Medicine - Ain Shams University

${ }^{3,4}$ MD Clinical Pathology, Lecturer of Clinical Pathology, Clinical Pathology Dept, Ain Shams University Corresponding Author

\section{Mona Fathey Abdel Fattah}

4 Eletreby Basha Abo Elezz, Heliopolis, Cairo, Egypt

Email: mona.fathey75@gmail.com, Mobile:0020201224579670

\begin{abstract}
Background: Fluorescence in situ hybridization (FISH) provides an important adjunct to molecular studies in the evaluation of chromosomal abnormalities in acute myeloid leukemia (AML), and is integral for diagnosis, prognosis and risk stratification according to professional clinical guidelines and WHO recent updates in 2016. The response of patients with AML to therapeutic modalities has been shown to be highly dependent upon disease characteristic and cytogenetic profile present at the time of diagnosis. This work aimed to detect specific chromosomal aberrations in AML patients, according to cytogenetic standards and professional quality assurance guidelines of clinical cytogenetics, by using Fluorescence in situ Hybridization (FISH) and assess their relation with other prognostic factors and therapeutic response.

Patients and Methods: FISH technique was used to detect $t(8 ; 21)(q 22 ; q 22), t(15 ; 17)(q 22 ; q 12), t(9 ; 22)$ (q34;q11), inv(16) (p13.1q22), 11q23 rearrangements, 17q rearrangements, inv(3q26), del 5q31, monosomy 5, del 7q31 and monosomy7 in 41 newly diagnosed adult AML patients.

Results and Conclusion: Application of FISH probes according to quality assurance guidelines ensures reliable chromosomal analysis with consistent interpretation of findings, including typical and atypical abnormal results in AML patients. Statistical analysis of patients' outcome with prognostic markers among newly diagnosed patients revealed significant association of poor therapeutic response to therapy with high TLC, and positive FISH analysis for $3 q 26$ (EVII) rearrangement, 11q23(MLL) rearrangements, t(9;22) $(B C R / A B L)$ and monosomy 7.

Keywords: $A M L, F I S H$, cytogenetic guidelines, quality assurance.
\end{abstract}




\section{Introduction}

All laboratories offering a cytogenetic service should be able to provide an accurate and precise analytical and interpretive service for all neoplasms that they deal with ${ }^{[1]}$. Fluorescence in situ hybridization (FISH) analysis becomes increasingly important in the clinical management of patients with different acute myeloid leukemia (AML) subgroups, some cytogenetic abnormallities provide important diagnostic \& prognostic information while others are cornerstone for tailor made therapy as $\mathrm{t}(15 ; 17)$ (PML/RARA) and $\mathrm{t}(9 ; 22) \quad$ (BCR/ABL) which represent new provisional entity in WHO 2016 update ${ }^{[2]}$.

Risk stratification based on pretreatment genetic signatures has become a critical step in the therapeutic decision-making process ${ }^{[3]}$. Whereas in younger patients diagnosed with AML treatment is straightforward and the goal is cure, the optimal treatment decision for older adult patients remains highly controversial ${ }^{[4]}$. Between $10 \%-40 \%$ of newly diagnosed AML patients do not achieve complete remission with intensive induction therapy and are therefore categorized as primary refractory or resistant. Few of these patients can be cured with conventional salvage therapy ${ }^{[5]}$.

In the light of this, this work aimed to detect specific chromosomal mutations in adult AML patients, according to quality assurance guidelines and recent WHO updates, by using Fluorescence in situ Hybridization (FISH) and assess their relation with other prognostic factors and therapeutic response.

\section{Subjects and Methods}

To achieve this aim, the present work was carried on 41 newly diagnosed adult AML patients, recruited from the Hematology oncology Unit, Ain Shams University hospitals and outpatients, during the period from May 2013 to May 2016. Out of the 41 patients, Sixteen (39\%) were males and twenty five $(61 \%)$ were females, with male to female ratio of (1:1.6). Their age ranged from 19 to 71 years with a mean $(45 \pm 26)$ years. Diagnosis was based on standard morphologic, cytochemical and immunophenotyping criteria.
Informed consent was obtained from patients to use their samples in this study. Patients were evaluated at day 28 of therapy throughout the period of the study to assess therapeutic response. All Patients were subjected to the following: Complete history taking and thorough clinical examination, laboratory investigations including: complete blood count using LH750 (Beckman coulter), examination of Leishman's stained peripheral blood films, bone marrow aspiration and examination of Leishman's stained bone marrow smears, cytochemical studies using myeloperoxidase stain. Immunophenotyping of bone marrow or peripheral blood samples using EPICS XL coulter flow cytometer to detect the FAB category, lactate dehydrogenase (LDH) was performed on Synchron CX-9 (Beckman Coulter, California, USA).

Fluorescence in situ hybridization analysis (FISH) analysis was performed according to Campbell ${ }^{[6]}$, following practice cytogenetic guidelines 2007 and 2010, Quality Assurance Guidelines $2013^{[1]}$ and analyzed by at least two of the trained team of specialists using Cyto Vision Leica Microsystem using the following probes: LSI RUNX1-RUNX1T1 for $\mathrm{t}(8 ; 21)(\mathrm{q} 22 ; \mathrm{q} 22)$, LSI PML-RARA for $\mathrm{t}(15 ; 17)(\mathrm{q} 22 ; \mathrm{q} 12)$, RARA break apart probe for detection of $17 \mathrm{q}$ rearrangements, LSI BCR-ABL for $\mathrm{t}(9 ; 22)(\mathrm{q} 34 ; \mathrm{q} 11)$, LSI CBFBMYH11 for inv(16)(p13.1q22), LSI MLL break apart for 11q23 rearrangements and LSI EVI1 break apart for inv(3q26), using the following probes: LSI 5q31 with LSI 5p15.2 control for detection of deletion $5 q 31$ and monosomy 5, LSI $7 \mathrm{q} 31$ with centromeric control for detection of deletion 7q31 and monosomy7.

\section{Sampling}

Peripheral blood and BM aspiration samples were collected under complete aseptic conditions into ethylene diamine tetra-acetic acid, potassium salt ( $\mathrm{K}_{2}$-EDTA) vacutainer for $\mathrm{CBC}$ and IPT. For cytogenetic analysis $1 \mathrm{~mL}$ of $\mathrm{BM}$ aspirate was collected into lithium heparin vacutainer, in addition to one $\mathrm{ml}$ peripheral blood (PB) in patients with PB blasts >10\%. Samples were 
collected with special emphasis of preanalytical precaution guidelines

\section{Cytogenetic analysis by FISH technique}

The culture conditions were optimized, Blocking agent (colcemid) was added to the culture medium before harvest. Slides were prepared from material fixed in methanol-acetic acid. All probes were set up (according to manufacturer guidelines /Vysis) separately on different slides for each patient (according to clinical, morphological and immunophenotyping characteristics). Hybridization and detection of hybridization signals were performed according to the manufacturer's protocols. To maximize the likelihood of detecting a neoplastic clone, 200 interphase cells were evaluated for each case using the CytoVision Leica Microsystem) in order to detect the target abnormalities. Images of FISH were captured through the program Mac Probe 4.4 of Power Gene System (Applied Imaging Corporation, USA). Thresholds and the confidence limit were established for all FISH probes and probe sets in cytogenetic lab, where the variation of aberrant signal patterns was documented for a number of 10 normal and 20 abnormal samples for each probe to give the false positive/negative ranges \& to check the signals intensity of the probes used. Interpretation of FISH probes was done according to manufacturer documentation. The limitations of the test was documented in the report.

\section{Definitions}

Complete remission (CR): $\mathrm{BM}$ blasts $\leq 5 \%$; absence of blasts with Auer rods; absence of extra medullary disease; absolute neutrophil count $>1 \times 10^{9} / \mathrm{L}$, platelets $>100 \times 10^{9} / \mathrm{L}$; independent of red cell transfusion. $C R$ with incomplete recovery (CRi): all the criteria for $\mathrm{CR}$ except for residual neutropenia $\left(<1 \times 10^{9} / \mathrm{L}\right)$ or thrombocytopenia $(<$ $\left.100 \times 10^{9} / \mathrm{L}\right)$. Partial remission (PR): all hematologic criteria of $\mathrm{CR}$; decrease of bone marrow blast percentage to $5 \%$ to $25 \%$; and decrease of pretreatment bone marrow blast percentage by at least $50 \%$. Treatment failure: (1) resistant disease (RD): failure to achieve CR or
$\mathrm{CRi}$, or failure to achieve $\mathrm{CR}, \mathrm{CRi}$, or PR; only includes patients surviving $\geq 7$ days following completion of initial treatment, with evidence of persistent leukemia by blood and/or bone marrow examination. (2) Relapse: Bone marrow blasts $\geq$ $5 \%$; or reappearance of blasts in the blood; or development of extramedullary disease ${ }^{[7]}$.

According to the national comprehensive cancer network (NCCN) guidelines ${ }^{[8]}$, the studied AML patient were classified into three risk groups; Favorable risk: $\mathrm{t}(15 ; 17)$, inv $(16) / \mathrm{t}(16 ; 16)$, or $\mathrm{t}(8 ; 21)$, Intermediate risk: normal cytogenetics, +8 alone, $\mathrm{t}(9 ; 11)$, other non defined, Poor risk: complex ( $\geq 3$ clonal chromosomal abnormalities), Monosomal karyotype: $-5,5 \mathrm{q}-,-7,7 \mathrm{q}-, \mathrm{t}(9 ; 22), \mathrm{t}$ $(6,9), \operatorname{inv}(3) / \mathrm{t}(3 ; 3), 11 \mathrm{q} 23$ non $\mathrm{t}(9 ; 11)$.

\section{Statistical Analysis}

Analysis of data was done using Statistical Program for Social Science version 20 (SPSS Inc., Chicago, IL, USA). Qualitative data were described in the form of number and percentage. Quantitative variables were described in the form of mean and standard deviation (SD) or median and inter-quartile range (IQR). In order to compare quantitative parametric variables between two groups, Student t-test was applied. Comparison between nonparametric variables was carried out using Mann-Whitney U test. Comparison between groups regarding qualitative data was performed by using Chi square $\left(\mathrm{X}^{2}\right)$ test. $\mathrm{p}$ value $<0.05$ was considered significant.

\section{Results}

Immunophenotyping (IPT): The studied 41 AML patients were expressing CD13 and CD33. Among them HLA-DR was negative in six (14.6\%) patients, CD14 was positive in twelve (29.3\%) patient, neuron-glial antigen 2 (NG2) was investigated in the two patients of AML-M5 only and revealed positive expression in both of them, while glycophorin A was negative in all patients, with aberrant expression of CD19,CD4,CD2, CD38 in some cases. 


\section{Fluorescence in Situ Hybridization Analysis}

Metaphase and/or interphase FISH analysis were successfully performed on $41 \mathrm{BM}$ and PB samples following professional guidelines to avoid general technical problems that may influence a test result, such as poor slide preparation, chromosomes or interphase nuclei of poor morphology with reduced signal intensity, or over- or under denaturation and revealed the following (table 1):

\section{Numerical aberration}

Monosomy 7 (-7) was encountered in two (4.9\%) patients. Trisomy $8(+8)$ was detected in two $(4.9 \%)$, while monosomy 5 was detected in one $(2.4 \%)$ patient only.

\section{Structural aberrations}

Flourescence in situ hybridization (FISH) analysis yielded four patients positive for $t(8 ; 21)$ (RUNX1/RUNX1T1), all were M1/ M2 and showed a variable degree of myelodysplasia in granulocytic series only with hyposegmentation and hypogranularity in addition to the presence of perinuclear hof and auer rods in blasts of two patients, with a characteristic immunophenotypic pattern of aberrant expression of CD19 in all positive cases .

The $t(15 ; 17)($ PML/RARA) was found in five cases that were diagnosed as M3 and they showed a predominance of hypergranular promyelocytes and blast cells, with a characteristic immunophenotypic pattern of HLA-DR and CD34 negative, while was negative in one patient with $\mathrm{M} 3 \mathrm{v}$ presented with high TLC and hypogranular promyelocytes. LSI 17q (RARA break apart probe) was applied for this patient, yielded positive result which reflected the presence of $17 q$ rearrangements with other partner chromosome rather than 15 .

The inv (16) was detected in 5/41 (12.2\%) cases were diagnosed as M4, four of them showed eosinophilia with a characteristic immunophenotypic pattern with aberrant expression of CD2.As regard 11q23 rearrangement, 2/41 (4.9 $\%$ ) cases were positive for it, both were diagnosed as M5b and showed (NG2) positive expression. One of the three patients with EVI1 inv (3q26) were M1/ M2, the second was M4 and the last one was M5, they showed variable degrees of multilineage dysplasia especially in megakaryocytes, with aberrant expression of CD38 in two of them.

\section{Follow up \& clinical outcome of studied all patients}

Follow up was done at day 28 of chemotherapy and throughout the period of the study. Out of the 41 newly diagnosed patients, thirty $(73.2 \%)$ patients achieved remission; while eleven $(26.8 \%)$ patients showed incomplete remission

\section{Prognostic Markers in Association to Patients Outcome}

Statistical analysis of patients' outcome with prognostic markers among newly diagnosed patients revealed significant association $(\mathrm{p}<0.05)$ of CR with TLC $<50 \times 10^{\wedge} 9 / \mathrm{L}(\mathrm{p}=0.000)$, sex $(\mathrm{p}=0.001)$ and FISH regarding it's prognostic classification (Table 3). On the other hand, age, hepatomegaly, splenomegaly, $\mathrm{Hb}$ concentration, platelet count and IPT showed non-significant statistical difference between the patients who achieved complete remission and those with incomplete remission ( $p>0.05$ ) (table 2). 
Table (1): FISH pattern of newly diagnosed AML patients :

\begin{tabular}{|c|c|c|c|c|c|}
\hline Case No. & \multicolumn{3}{|c|}{ Interpretation of FISH } & $\%$ & Outcome \\
\hline $\begin{array}{l}1,3,11,16,20,21 \\
22,34,35,37,41\end{array}$ & \multicolumn{3}{|c|}{ Normal signals pattern according to the used probe } & $26.8 \%$ & $\mathrm{CR}$ \\
\hline \multicolumn{6}{|c|}{ Abnormal signals pattern } \\
\hline Case No & Result & $\begin{array}{l}\text { Involved } \\
\text { Genes }\end{array}$ & $\begin{array}{l}\text { Involved Chromosomal } \\
\text { bands and regions }\end{array}$ & $\%$ & Outcome \\
\hline $13,14,15,29,30$ & Inv16/t(16;16) & CBFB/MYH11 & $\mathrm{p} 13 ; \mathrm{q} 22$ & $12.2 \%$ & $\mathrm{CR}$ \\
\hline 8,9 & $\begin{array}{l}11 \mathrm{q} 23 \\
\text { Rearrangements }\end{array}$ & MLL & $\mathrm{q} 23$ & $4.9 \%$ & IR \\
\hline 18,36 & Monosomy 7 & $\begin{array}{l}\text { All genes located on } \\
\text { chromosome } 7\end{array}$ & $7 q 31$ & $4.9 \%$ & IR \\
\hline 19 & Monosomy5 & $\begin{array}{l}\text { All genes located on } \\
\text { chromosome } 5\end{array}$ & $5 q 31$ & $2.4 \%$ & IR \\
\hline $2,17,31$ & $\begin{array}{l}3 \mathrm{q} 26 \\
\text { Rearrangements }\end{array}$ & EVI1 & & $7.3 \%$ & IR \\
\hline $25,26,27,28$ & $\begin{array}{l}\mathrm{t}(8 ; 21) \\
\text { as a sole anomaly }\end{array}$ & RUNX1/RUNX1T1 & $(8 \mathrm{q} 22 ; 21 \mathrm{q} 22)$ & $9.8 \%$ & $\mathrm{CR}$ \\
\hline 12,38 & $\begin{array}{l}\text { Trisomy } 8(+8) \\
\text { as a sole anomaly }\end{array}$ & ETO & $(8 \mathrm{q} 22)$ & $4.9 \%$ & $\mathrm{CR}$ \\
\hline 39 & $\mathrm{t}(9 ; 22)$ & BCR/ABL & $(9 \mathrm{q} 34 ; 22 \mathrm{q} 11)$ & $2.4 \%$ & IR \\
\hline $4,5,7,23,24$ & $\mathrm{t}(15 ; 17)$ & PML/RAR- $\alpha$ & $(15 \mathrm{q} 22 ; 17 \mathrm{q} 21)$ & $12.2 \%$ & CR \\
\hline 6 & $\begin{array}{l}17 q \\
\text { Rearrangement }\end{array}$ & RAR- $\alpha$ & $(17 \mathrm{q} 21)$ & $2.4 \%$ & IR \\
\hline 10,3233 & $\operatorname{del} 5 q$ & EGR1 & $5 q 31$ & $7.3 \%$ & \begin{tabular}{|l} 
CR: No $10 \& 32$ \\
IR.
\end{tabular} \\
\hline 40 & $\begin{array}{l}\begin{array}{l}\text { Others } \\
\text { (Amplification } \\
\text { BCR Gene) }\end{array} \\
\end{array}$ & BCR & (22q11) & $2.4 \%$ & $\mathrm{CR}$ \\
\hline
\end{tabular}

del: deletion, CR: Complete remission, IR: In Complete remission, FISH: fluorescence in situ hybridization.

Table (2): Results of AML patients' outcome in relation to different prognostic factors

\begin{tabular}{|c|c|c|c|c|c|c|c|c|}
\hline \multirow{2}{*}{ Parameter } & \multirow[b]{2}{*}{ Groups } & \multirow{2}{*}{ No. } & \multirow{2}{*}{$\%$} & \multicolumn{2}{|l|}{ CR } & \multicolumn{2}{|l|}{ IR } & \multirow{2}{*}{$\mathbf{P}$} \\
\hline & & & & No. & $\%$ & No. & $\%$ & \\
\hline Age (Years) & $\begin{array}{l}\geq 60 \\
<60\end{array}$ & $\begin{array}{l}11 \\
30\end{array}$ & $\begin{array}{l}26.2 \\
73.2\end{array}$ & $\begin{array}{l}6 \\
24\end{array}$ & $\begin{array}{l}20.0 \\
80.0\end{array}$ & $\begin{array}{l}5 \\
6\end{array}$ & $\begin{array}{l}45.5 \\
54.5\end{array}$ & 0.128 \\
\hline $\begin{array}{l}\text { Sex } \\
\delta: \text { o }(1: 1.6)\end{array}$ & $\begin{array}{l}\text { Male } \\
\text { Female }\end{array}$ & $\begin{array}{l}16 \\
25\end{array}$ & $\begin{array}{l}39.0 \\
61.0\end{array}$ & $\begin{array}{l}7 \\
23\end{array}$ & $\begin{array}{l}23.3 \\
76.7\end{array}$ & $\begin{array}{l}9 \\
2 \\
\end{array}$ & $\begin{array}{l}81.8 \\
18.2 \\
\end{array}$ & 0.001 \\
\hline Hepatomegaly & $\begin{array}{l}\text { Yes } \\
\text { No }\end{array}$ & $\begin{array}{l}14 \\
27\end{array}$ & $\begin{array}{l}34.1 \\
65.9\end{array}$ & $\begin{array}{l}8 \\
22\end{array}$ & $\begin{array}{l}26.7 \\
73.3\end{array}$ & $\begin{array}{l}6 \\
5\end{array}$ & $\begin{array}{l}54.5 \\
45.5\end{array}$ & 0.140 \\
\hline Splenomegaly & $\begin{array}{l}\text { Yes } \\
\text { No }\end{array}$ & $\begin{array}{l}19 \\
22\end{array}$ & $\begin{array}{l}46.3 \\
53.7\end{array}$ & $\begin{array}{l}12 \\
18\end{array}$ & $\begin{array}{l}40.0 \\
60.0\end{array}$ & $\begin{array}{l}7 \\
4 \\
\end{array}$ & $\begin{array}{l}63.6 \\
36.4\end{array}$ & 0.179 \\
\hline $\mathrm{Hb}$ & $<10 \mathrm{~g} / \mathrm{dl}$ & 41 & 100 & 30 & 73.2 & 11 & 26.8 & \\
\hline $\operatorname{TLC}\left(x 10^{9} / \mathrm{L}\right)$ & $\begin{array}{l}<50 \\
\geq 50\end{array}$ & $\begin{array}{l}31 \\
10\end{array}$ & $\begin{array}{l}75.6 \\
24.4\end{array}$ & $\begin{array}{l}29 \\
1\end{array}$ & $\begin{array}{l}96.7 \\
3.3\end{array}$ & $\begin{array}{l}2 \\
9\end{array}$ & $\begin{array}{l}18.2 \\
81.8\end{array}$ & 0.000 \\
\hline $\begin{array}{l}\text { Platelet count } \\
\left(\mathrm{x} 10^{9} / \mathrm{L}\right)\end{array}$ & $\begin{array}{l}<100 \\
\geq 100\end{array}$ & $\begin{array}{l}40 \\
1\end{array}$ & $\begin{array}{l}97.6 \\
2.4\end{array}$ & $\begin{array}{l}29 \\
1\end{array}$ & $\begin{array}{l}96.5 \\
3.3 \\
\end{array}$ & $\begin{array}{l}11 \\
0\end{array}$ & $\begin{array}{l}100 \\
0.0\end{array}$ & 1.00 \\
\hline IPT (FAB) & $\begin{array}{l}\text { M0 } \\
\text { M1/M2 } \\
\text { M3 } \\
\text { M4 } \\
\text { M5 }\end{array}$ & $\begin{array}{l}1 \\
21 \\
6 \\
7 \\
6\end{array}$ & \begin{tabular}{|l|}
2.4 \\
51.2 \\
14.6 \\
17.1 \\
14.6
\end{tabular} & \begin{tabular}{|l|}
0 \\
16 \\
5 \\
6 \\
3 \\
\end{tabular} & \begin{tabular}{|l|}
0.00 \\
53.3 \\
16.7 \\
20.0 \\
10.0
\end{tabular} & $\begin{array}{l}1 \\
5 \\
1 \\
1 \\
3\end{array}$ & $\begin{array}{l}9.1 \\
45.5 \\
9.1 \\
9.1 \\
27.3\end{array}$ & 0.254 \\
\hline FISH & $\begin{array}{l}\text { Favorable } \\
\text { Intermediate } \\
\text { Unfavorable }\end{array}$ & $\begin{array}{l}14 \\
14 \\
13 \\
\end{array}$ & \begin{tabular}{|l|}
34.1 \\
34.1 \\
31.7 \\
\end{tabular} & \begin{tabular}{|l|}
14 \\
14 \\
2 \\
\end{tabular} & \begin{tabular}{|l|}
46.7 \\
46.7 \\
6.7 \\
\end{tabular} & $\begin{array}{l}0 \\
0 \\
11 \\
\end{array}$ & $\begin{array}{l}0 \\
0 \\
100.0\end{array}$ & 0.00 \\
\hline
\end{tabular}

TLC: total leucocytic count Hb: hemoglobin, IPT: Immunophenotyping, CR: Complete remission, IR: In Complete remission, FISH: fluorescence in situ hybridization, 


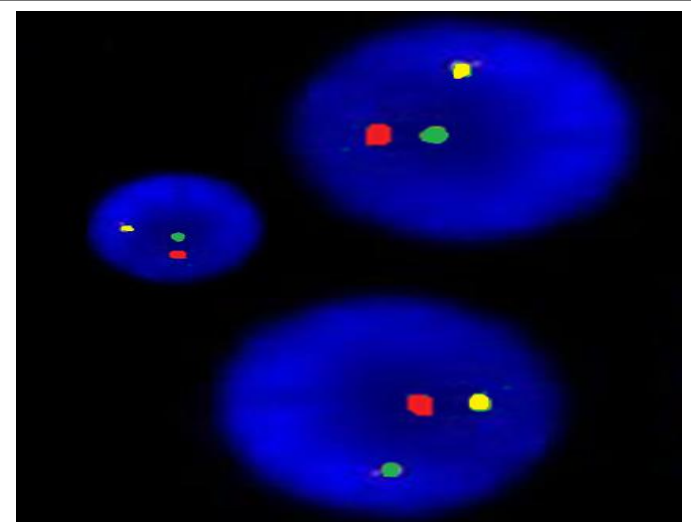

Figure. (1): LSI CBFB Break Apart FISH Probe revealed positive result for $\operatorname{INV} 16 / \mathrm{T}(16 ; 16)$ identified by the presence of 1 yellow signal (normal copy of chromosome 16)in addition to the spitted red and green (rearranged chromosome 16) signals.

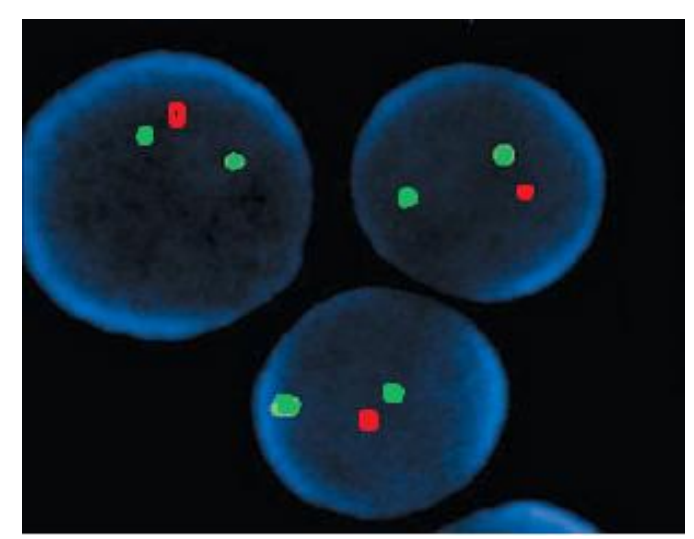

Figure. (2): LSI EGR1 FISH Probe in red with centromeric control in green revealed positive result for del 5q31 identified by the presence of 1 red signal \{one copy only of 5q31(EGR1) \} in addition to the two green signals (two centromeres of both copies of chromosome 5)

\section{Discussion}

Quality assurance has an increasingly important role in cytogenetic diagnostic service, when looking for small deletions/duplications, cryptic chromosomal abnormalities, expansion of normal clone in some cases, FISH technique is integral to diagnosis of chromosomal analysis. In view of rapidly changing practices and technology, FISH applications according to quality assurance guidelines taking in consideration the preanalytical precautions will ensure the robustness of cytogenetic results.
Over the past decade, the explosion of molecular biology research and improvement in cytogenetic and molecular techniques, has led to the identification and study of genes involved in recurring numerical and structural chromosomal aberrations in AML. Although a large number of aberrations have been cloned, many of the identified genes are postulated as being important in establishing the subtypes of AML [9]. Characterization of AML patients according to presentation cytogenetic profile provides an important basis for designing novel therapeutic strategies that target specific genetic abnormalities in leukemic blasts ${ }^{[10]}$. Improved characterization and standardization of morphological and immunophenotypic features aided in the differentiation of disease subgroups, and the accurate selection of appropriate FISH probe.

To achieve our aim, metaphase and interphase FISH analysis were applied for 41 newly diagnosed adult AML patients, following the quality assurance guidelines as regard pre-analytical precautions, analytical guidelines of manufacturer and postanalytical reporting requirements. Application of FISH probes were based on morphologic, cytochemical and immunophenotypic diagnostic criteria for AML.

In the present study, abnormal cytogenetic profile was detected in higher percentage of patients, as presented in $26(63.4 \%)$ patients, $23(88.5 \%)$ out of them achieved $\mathrm{CR}$, while normal cytogenetic profile was detected in $15(36.6 \%)$ patients, all of them succeeded to achieve CR at day 28, however, long term follow up may change this observation. This was in agreement with the previous findings of Breems et al ${ }^{[11]}$ and Hamad et al ${ }^{[12]}$ who noticed a high rate of CR in patients with normal pattern, presented in $87 \%$ and $100 \%$ patients respectively. Concerning these ratios, they concluded good prognostic influence of cytogenetically- normal AML on the outcome. On the other hand, Fasan et al ${ }^{[13]}$ and Heim and Mittelman ${ }^{[14]}$ considered normal cytogenetic profile in AML patients as an intermediate prognostic factor as it might hide a cryptic or minute aberration which necessitate a molecular technique to detect it. 
At the same point of view, Döhner and Döhner ${ }^{[15]}$ and Bryan and Jay ${ }^{[16]}$ reported that in patients with normal cytogenetic profiling, several molecular abnormalities (mutations) have been shown to have prognostic importance. They identified FLT3 Internal tandem duplications (ITDs) in the juxta membrane domain of FLT3 as the most commonly mutated gene in AML (seen in $25 \%$ of AML cases). Mutation in NPM1 is generally favorable; patients with this mutation show increased response to chemotherapy and improved survival (changes otherwise intermediate-risk patients into better-risk). However, if present together with the FLT3 mutation, this survival benefit is negated. Mutations in CEBPA are detected in $10-15 \%$ of patients with normal cytogenetics and are associated with a longer remission duration and longer overall survival ${ }^{[13,17,18]}$. Of note, the presence of c-KIT mutations confers a higher risk of relapse and would place an otherwise betterrisk patient into the intermediate-risk category ${ }^{[19]}$. In the present study, numerical aberrations were encountered in $6(14.6 \%)$ patients, with monosomy 7 as the most common one, representing $3(7.3 \%)$ of newly diagnosed patients, all of them encountered as a sole anomaly where none of them achieved complete or even partial remission to standard induction chemotherapy. This is consistent with the previous works that consider monosomy 7 AML has a particularly very poor prognosis and hence in need to intensive chemotherapy and early bone marrow transplantation that are likely to offer best chance for survival ${ }^{[20]}$. The previous observation may be attributed to loss of tumor suppressor genes present on chromosome $7^{[21]}$.

In the current work, trisomy 8 was observed in 2/41 (4.9\%), in agreement with Wolman et al. ${ }^{[22]}$, who stated that trisomy 8 occur at frequency of $5.1 \%$ as a sole anomaly, while Bakshi et al. ${ }^{[23]}$, reported a higher prevalence of trisomy 8 of about $15 \%$ of AML patients. As regard their outcome, complete remission was achieved in all +8 positive patients $(100 \%)$. Similarly, Elliott et al. ${ }^{[24]}$ reported that $\mathrm{CR}$ was achieved in $85 \%$ of patients with isolated +8 .

German AML Co-operative Study Group followed up 51 AML patients and found that patients with +8 as the sole cytogenetic anomaly had an intermediate prognosis, patients with +8 in addition to favorable chromosome aberrations $(\mathrm{t}(8 ; 21), \mathrm{t}(15 ; 17), \operatorname{inv}(16))$ maintained a good clinical outcome, and patients with +8 in combination with other abnormalities showed the worst prognosis ${ }^{[25]}$. They concluded that the presence of +8 appears to be dependent on other associated clonal cytogenetic changes. In contrast, Wolman et al. ${ }^{[22]}$ and Paulsson et al. ${ }^{[26]}$ have suggested that patients with trisomy 8 have poor overall survival and not do response to therapy.

Moreover, in the present study structural cytogenetic aberrations were detected in $24 / 41$ (58.5\%) of patients. They had chromosomal abnormalities restricted to AML in the form of $\mathrm{t}(15 ; 17), \mathrm{t}(8 ; 21), \operatorname{inv}(16)$, del 5q, 11q23, 17q, $\operatorname{EVI} 1(3 \mathrm{q} 26) \& \mathrm{t}(9 ; 22)$.

The $\mathrm{t}(15 ; 17)$ was found in five cases that were diagnosed as M3 and they showed a characteristic immunophenotypic pattern of HLA-DR and CD34 negative; all patients achieved complete remission . McKinney et al. ${ }^{[27]}$ and Sucic et al. ${ }^{\text {[28] }}$ stressed on the point that not only $t(15 ; 17)$ is restricted to M3, but also practically, all M3 patients had this translocation at DNA levels even if karyotypically normal. Consistent with Grimwade and Solomon ${ }^{[29]}$ and Chen et al ${ }^{[30]}$, this rearrangement is firmly established as remarkably APL associated cytogenetic abnormality classified among favorable group. Moreover, Chauffaille et al. [31] stated that interphase FISH can detect $\mathrm{t}(15 ; 17)$ in $100 \%$ of tested samples in comparison to $70 \%$ detection by karyotyping.

Regarding $\mathrm{t}(8 ; 21), 4 / 41$ (9.8\%) cases harbor it as a sole anomaly; all were M1/ M2 and showed a variable degree of myelodysplasia in granulocytic series in the form of hyposegmentation and hypogranularity in addition to the presence of auer rods in blasts which goes in agreement with WHO 2008. These cases showed a characteristic 
immunophenotypic pattern of aberrant expression of CD19. The same observation was previously confirmed by WHO 2008 which identified AML with $t(8 ; 21)$ as subtype displaying a characteristic immunophenotype with a sub population of blast cells showing high intensity expression of CD34, together with HLA-DR, MPO and CD13, relatively weak expression of $\mathrm{CD} 33$; aberrant CD19 and CD56 (natural killer) may be expressed, however CD56 was not investigated in our work.

All the $t(8 ; 21)$ positive patients in this work achieved complete remission at day 28. This finding is consistent with Yuan et al. ${ }^{[32]}$ and Lowenberg et al. ${ }^{[33]}$ who reported that, $t(8 ; 21)$ is one of the most frequent chromosomal abnormalities associated with M2 and they correlated its expression with a direct involvement in the development of AML and with favorable prognosis. On the other hand, Shimada et al. ${ }^{[19]}$ claimed that although $\mathrm{t}(8 ; 21)$ AMLs are reported to have good prognosis, yet approximately (50\%) of them relapse, with (ITD) of FLT3 and/or KIT mutations being encountered in $(12.7 \%)$ to (48.1\%) of adult patients with poor outcome AML.

The third type of translocation detected in the current work was inv(16), it was detected in 5/41 ( $12.2 \%$ ) cases ; all were diagnosed as M4. On the contrary, Shurtleff et al. ${ }^{[34]}$ reported that, although inv (16) classically has been associated with FABM4Eo morphology, it is not limited to this subtype. The positive patients showed a characteristic immunophenotypic pattern with aberrant expression of $\mathrm{CD} 2$, in agreement with WHO 2008 which sated that AML-M 4 express the pan-myeloid marker CD13 and the stem cell antigen CD34, but there is variable expression of CD11b, CD11c, CD14 and CD33 with frequent expression of the T-lymphoid marker $\mathrm{CD}_{2}$. All of our patients achieved complete remission which is consistent with previous works considered inv(16) as the most favorable cytogenetic abnormality as complete remission rates of $(76 \%)$ to $(92 \%)$ have been reported ${ }^{[35]}$.
In the current work, as regard $11 \mathrm{q} 23$ rearrangement, $2 / 41(4.9 \%)$ cases were positive for it, both of the 2 cases were diagnosed as M5b and they failed to achieve complete remission. In two studies done by Chen et al. ${ }^{[30]}$ and Gröschel et al. ${ }^{[36]}$, all patients with this rearrangement died prior to chemotherapy which confirmed the bad prognostic value of 11q23. The WHO 2008 stated that most AML cases with 11q23 abnormalities express the NG2 homologue in consistence with results in our study

Regarding EVI1 (3q26) rearrangements, 3/41 (7.3\%) cases showed positive signals; the first one was M1/ M2, the second was M4 and the last one was M5, they showed a characteristic multilineage dysplasia especially in megakaryocytes, this observation was confirmed by WHO 2008 which reported a peripheral blood with hypogranular neutrophils with a pseudo PelgerHuet anomaly, and a BM with morphologic multilineage dysplasia. None of the three patients achieved complete remission, which was also reported by WHO 2008.

As The WHO recent classification of myeloid neoplasms in 2016 emphasizes the importance $\mathrm{t}(9 ; 22)(\mathrm{BCR} / \mathrm{ABL})$ in AML, it was investigated in al patients in current study, and was detected in one patient $(2.4 \%)$ only that was diagnosed as M1/M2 and showed incomplete remission. Interestingly, a new provisional category of AML with BCR-ABL1 is added to AML subgroups in WHO revised version for classification of myeloid neoplasms and acute leukemia recognizing these rare de novo AML cases that may benefit from tyrosine kinase inhibitor (TKI) therapy. Although the diagnostic distinction between de novo AML with BCR-ABL1 and blast transformation of CML may be difficult without adequate clinical information, the significance of detecting this targetable fusion is felt to warrant a provisional disease category. Preliminary data suggest that deletion of antigen receptor genes (IGH, TCR), IKZF1 and/or CDKN2A may support a diagnosis of de novo disease versus $\mathrm{BP}$ of $\mathrm{CML}{ }^{[2]}$. Interestingly 1 AML case (AML-M2) only showed negative signals for ph while multiple 
copies of green signals denoting amplification of BCR gene located at 22q11, the patient achieved complete remission, it is a novel finding and as it was detected in 1 patient only, its prognostic impact cannot be justified.

In conclusion, thorough clinical \& morphological examination together with immunophenotyping pattern provide a solid framework for selective application of appropriate fluorescence in situ hybridization probes in AML patients. Riskstratification schemes using initial TLC and cytogenetic analysis following quality assurance and professional cytogenetic guidelines are significant indicators of patients outcome. The presence of certain cytogenetic aberrations such as 3q26 (EVI1) rearrangement, 11q23(MLL) rearrangements, $\mathrm{t}(9 ; 22)(\mathrm{BCR} / \mathrm{ABL})$ and monosomy 7 are confirmed to be correlated with poor therapeutic response despite the low number of patients. Application of FISH probes according to quality assurance guidelines ensures reliable chromosomal analysis with consistent interpretation of findings, including typical and atypical abnormal results in AML patients.

\section{References}

1. Hastings R, Howell R, Betts D, Porter S, Haferlach C, Dastugue N, Radford-Weiss I, Beverloo H, Simons A, Mellink C, Snijder S, Ruiter E, Schoumans J, Espinet B, Siebert R, Couturier J, Bernheim A, Solé F, Luquet I, Stioui S, Cavani S. Guidelines and Quality Assurance for Acquired Cytogenetics A common European framework for quality assessment for banded chromosome studies and molecular cytogenetic investigations of acquired abnormalities. European Cytogenetics Association Newsletter. 2013; No 13.

2. Arber DA, Orazi A, Hasserjian R, Thiele J, Borowitz MJ, Le Beau MM, Bloomfield CD, Cazzola M, Vardiman JW. The 2016 revision to the World Health Organization classification of myeloid neoplasms and acute leukemia.

Blood. 2016;127:2391-2405.

3. Chotirat S, Thongnoppakhun W, Promsuwicha O, Boonthimat $\mathrm{C}$ and Auewarakul C. Molecular alterations of isocitrate dehydrogenase 1 and 2 (IDH1 and IDH2) metabolic genes and additional genetic mutations in newly diagnosed acute myeloid leukemia patients. Journal of Hematology and Oncology. 2012; 5: 5.

4. Eleni LD, Nicholas ZC, Alexandros S. Challenges in treating older patients with acute myeloid leukemia. Journal of oncology. 2010;2010: 823-943

5. Thol F, Schlenk RF, Heuser M, Ganser A. How I treat refractory and early relapsed acute myeloid leukemia. Blood. 2015; 26(3): 319-327.

6. Campbell L. Cytogenetic and FISH techniques in myeloid malignancies. Methods Mol Med. 2006; 125: 13-28.

7. Dohner H, Estey EH, AmadoriS, Appelbaum FR, Buhner T, Burnett A, Dombret H, Fenaux P, Grimwade D, Larson RA, Lo-Coco F, Naoe T, Niederwieser D, Ossenkoppele GJ, Sanz MA, Sierra J, Tallman MS, Lo Wenberg B, Bloomfield CD. Diagnosis and management of acute myeloid leukemia in adults: recommendations from an international expert panel, on behalf of the European Leukemia Net. Blood. 2010; 115: 453-474.

8. O'Donnell MR, Tallman MS, Abboud CN, Altman JK, Appelbaum FR, Arber DA, Altar E, et al. Acute myeloid leukemia: NCCN clinical practice guidelines in oncology. National Comprehensive Cancer Network On- Line. 2014; 2

9. Baer $M$ and Greer J. In Acute myeloid leukemia in adults. In: Wintrobe's clinical hematology. Greer JP, Arber DA, Glader B, List Af, Jr RTM, Paraskevas F, Rodgers GM and Foester J (eds.), (13th edition), Lippincott Williams and Wilkins, Wolters Kluwer 
Health, Philadelphia, USA. 2009; Chapter 79: 1843-1846.

10. Sole F, Florensa L, Espinet B, Basses C, Lioveras $\mathrm{E}$ and Woessner S. Absence of BCR/ABL rearrangement in 41 patients with essential thrompocytopenia. Haematologica. 2000; 85: 214-215.

11. Breems D, Van Putten W, Georgine E, Greef D, Shama L, Bhola V, Klasien B, Schoorl G, Clemens H, Mellink, Nieuwint A, Jotterand $\mathrm{M}$, Hagemeijer $\mathrm{A}$, Beverloo $\mathrm{H}$, and Lowenberg B. Monosomal Karyotype in Acute Myeloid Leukemia: A Better Indicator of Poor Prognosis Than a Complex Karyotype. Journal of Clinical Oncology. 2008; 26: 4791-4797.

12. Hamad N, Elconin J, Karnoub A, Bai W, Rich J, Abraham R, Der C. Distinct requirements for Ras oncogenesis in human versus mouse cells. Genes \& Dev. 2002; 16 : 2045-57.

13. Fasan A, Haferlach C, Alpermann T, Kern W, Haferlach $\mathrm{T}$ and Schnittger S. A rare but specific subset of adult AML patients can be defined by the cytogenetically cryptic NUP98-NSD1 fusion gene. Leukemia. 2013; 27: 245-248.

14. Heim S and Mittelman F. Acute myeloid leukemia. Cancer Cytogenetics. 1995; 2nd ed. New York: Willey-Liss: 69-140.

15. Döhner $\mathrm{K}$ and Döhner $\mathrm{H}$. Molecular characterization of acute myeloid leukemia. Haematologica. 2008; 93: 976-982.

16. Bryan L and Jay L. Acute Myeloid Leukemia Diagnosis in the 21st Century. Arch Pathol Lab Med. 2010; 134: 1427-1433.

17. Kim S, Kim D, Jang J, Jung C and Jang M. Novel mutations in CEBPA in Korean Patients with acute myeloid leukemia with a normal karyotype. Ann Lab Med. 2012; 32: 153-157.

18. Kayser S, Zucknick M, Döhner K, Krauter J, Köhne C, Horst H, Held G, T-Toal, Wilhelm S, Rummel T, Germing U, Götze K, Nachbaur D, Schlegelberger B, Göhring G, Späth D, Morlok C, Teleanu V, Ganser A,
Döhner H, Schlenk R, and for the GermanAustrian AML Study Group. Monosomal karyotype in adult acute myeloid leukemia: prognostic impact and outcome after different treatment strategies. Blood. 2012; 119: 551558.

19. Shimada A, Taki T, Tabuchi K, Tawa A, Horibe K, Tsuchida M, Hanada R, Tsukimoto I, and Hayashi Y. KIT mutations, and not FLT3 internal tandem duplication, are strongly associated with a poor prognosis in pediatric acute myeloid leukemia with $\mathrm{t}(8$; 21): a study of the Japanese Childhood AML Cooperative Study Group. Blood. 2006; 107: 1806-1809.

20. Evans J, Czepulkowski B, Gibbons B, Swansbury G and Chessells J. Childhood monosomy 7 revisited. Br J Haematol.1988; 69: 41-5.

21. Warner JK, Wang JY, Hope KJ, Jin L and Dick JE. Concepts of human leukemic development. Oncogene. 2004; 23: 7164 7177.

22. Wolman S, Gundacker H, Appelbaum F, and Slovak M. Impact of trisomy 8 on clinical presentation, treatment response and survival in acute myeloid leukemia: a Southwest Oncology Group study. Blood. 2002; 100: 29-35.

23. Bakshi S, Brahmbhatt M, Trivedi P, Dalal E, Patel D, Purani S, Shukla S, Shah P and Patel P. Trisomy 8 in leukemia; A GCRI experience. Indian Journal of Human Genetics. 2012; 18: 106-108.

24. Elliott M, Letendre L, Tefferi A, Hanson C and Dewald G. Trisomy 8 in acute myeloid leukemia (AML). Blood. 2000; 96: 708.

25. Schoch C, Haase D, Fonatsch C, Haferlach T, Löffler H, Schlegelberger B, Hossfeld D, Becher R, Sauerland M, Heinecke A, Wörmann B, Büchner T, Hiddemann W and for the German AML Cooperative Study Group. The significance of trisomy 8 in de novo acute myeloid leukaemia: the accompanying chromosome aberrations 
determine the prognosis. British Journal of Haematology. 1997; 99: 605-611.

26. Paulsson K, Lassen C, Kuric N, Billstrom R, Fioretos T, Tanke H and Johansson B. MYC is not overexpressed in a case of chronic myelomonocytic leukemia with MYCcontaining double minutes. Leukemia. 2003; 17: 813-816.

27. McKinney C, Golden W, Gemma N, Swerdlow S and Williams M. RARA and PML gene rearrangements in acute promyelocytic leukemia with complex translocations and atypical features. Genes Chromosomes Cancer. 1994; 9: 49-56.

28. Sucić M, Zadro R, Burazer B, Labar B, Nemet D, Mrsić M, Aurer I, Mrsić S, Hitrec $\mathrm{V}$, Boban D, Glamocak M, Batinić D, Uzarević B and Rukavina A. Acute promyelocytic leukemia M3: cytomorphologic, immunophenotypic, cytogenetic, and molecular variants. J Hematother Stem Cell Res. 2002; 11(6): 941-50.

29. Grimwade D and Solomon E. Characterisation of the PML/RAR alpha rearrangement associated with $\mathrm{t}(15 ; 17)$ acute promyelocytic leukaemia. Curr Top Microbiol Immunol. 1997; 220: 81-112.

30. Chen Y, Kantarjian H, Pierce S, Faderl S, O’Brien S, Qiao W, Abruzzo L, De Lima M, Kebriaei P, Jabbour E, Daver N, Kadia T, Estrov Z, Garcia-Manero G, Cortes $\mathrm{J}$ and Ravandi F. Prognostic significance of 11q23 aberrations in adult acute myeloid leukemia and the role of allogeneic stem cell transplantation. Leukemia. 2013; 27: 836-842.

31. Chauffaille $M$, Figueiredo $M$, Beltrani $R$, Antunes S, Yamamoto $\mathrm{M}$ and Kerbauy J. Acute promyelocytic leukemia: the study of $\mathrm{t}$ $(15 ; 17)$ translocation by fluorescent in situ hybridization, reverse transcriptasepolymerase chain reaction and cytogenetic techniques. Research. 2001; 34: 735-743.
32. Yuan Y, Zhou L, Miyamoto T, Iwasaki H, Christopher J, Sebastien A, Burel, Lagasse E, Weissman I, Akashiffi K, and Zhang D. AML1-ETO expression is directly involved in the development of acute myeloid leukemia in the presence of additional mutations. Proc Natl Acad Sci U S A. 2001; 98(18): 10398-10403.

33. Lowenberg B, Downing J and Burnett A. Acute Myeloid Leukemia. The New English Journal of Medicine. 1999; 341: 1051-1062.

34. Shurtleff SA, Meyers S, Hiebert SW, Raim ondi SC, Head DR, Willman CL, Wolman S, Slovak ML,Carroll AJ, Behm F, Hulsho f MG, Motroni TA, Okuda T, Liu P, Collin s FS, Downing JR. Heterogeneity in $\mathrm{CBFb} / \mathrm{MYH} 11$ fusion messages encoded by the inv(16)(p13q22) and the $\mathrm{t}(16 ; 16)(\mathrm{p} 13 ; \mathrm{q} 22)$ in acute myelogenous leukemia. Blood. 1995; 85: 3695.

35. Raidmondi $S$ and Heermema N. In Cytogenetics in children, adolescents and young adults; in ALL and AML. In Hematological Malignancies in Children, Adolescents and Young Adults, (first edition), Cairo MS and Sherrie L Perkins (eds.). 2012; Chapter 5: 101-120., Singapore; World Scientific.

36. Gröschel S, Sanders MA, Hoogenboezem $\mathrm{R}$, et al. Mutational spectrum of myeloid malignancies with $\operatorname{inv}(3) / t(3 ; 3)$ reveals a predominant involvement of RAS/RTK signaling pathways. Blood. 2015; 125(1): 133-139. 